Wilfrid Laurier University

Scholars Commons @ Laurier

$11-27-2018$

\title{
"Use It or Lose It": How Online Activism Moderates the Protective Properties of Gender Identity for Well-Being
}

Mindi D. Foster

Wilfrid Laurier University, mfoster@wlu.ca

Follow this and additional works at: https://scholars.wlu.ca/psyc_faculty

Part of the Gender and Sexuality Commons, and the Psychiatry and Psychology Commons

\section{Recommended Citation}

Foster, Mindi D. (2018). "Use It or Lose It": How Online Activism Moderates the Protective Properties of Gender Identity for Well-Being. Computers in Human Behavior, In Press, Accepted Manuscript, Available online 27 November 2018.

This Article is brought to you for free and open access by the Psychology at Scholars Commons @ Laurier. It has been accepted for inclusion in Psychology Faculty Publications by an authorized administrator of Scholars Commons@Laurier. For more information, please contact scholarscommons@wlu.ca. 


\begin{abstract}
Regardless of criticisms that online activism does nothing but increase positive feelings, there is merit to understanding the role of online activism for well-being. This research sought to integrate two separate but complimentary lines of research (the well-being effects of activism and social identity) by suggesting that online activism may enhance the ability of social identity to protect against the negative well-being consequences of pervasive discrimination. Three studies, each with different operational definitions of online activism, showed a similar pattern: online activism enhanced the relationship between gender identity and well-being. Consistent with theory on activism's role as a dynamic predictor of social identity (e.g., Drury \& Reicher, 1999), this research suggests that online activism, as a means by which social identity can be enacted, can strengthen the protective ability of social identity for well-being. Theoretical and practical implications of the benefits of online activism are discussed.
\end{abstract}

Key words: Online activism, identity, gender discrimination, well-being 


\section{Introduction}

Perhaps one of the most popular criticisms of online activism (e.g., directed emails, hashtags, clicking a 'like' button, or signing online petition; Lee \& Hsieh, 2013) is to label it "slacktivism," i.e., behaviors that have no impact other than to make us feel good (Mozorov, 2009). The debate over its effectiveness aside, (for accumulating evidence of the positive impact of online activism on offline activism, see Fatkin \& Landsdown, 2015; Milošević-Dordević \& Žežilj, 2017; Postmes \& Brunsting, 2002; Vaccari et al., 2015), there is stand-alone merit to examining the 'feel good' component of online activism. First, positive feelings and "feeling useful" (Mozorov, 2009) are part of the larger constructs of subjective (Diener, 1984) and psychological well-being (Ryff \& Keyes, 1985), which are consistent predictors of health (e.g., Diener \& Chang, 2011; Howell, Kern \& Lyubomirsky, 2007; Ryff, 2013). Thus, if online activism helps to enhance well-being, then those participating will benefit. Second, it has been widely documented within learning theory that behaviors followed by positive consequences are repeated, whereas those followed by negative consequences are avoided (Skinner, 1971). Thus, criticizing online activism for merely promoting good feelings may be counter-productive, when in fact, those good feelings may positively reinforce activist behavior, thereby promoting future activism. As such, the goal of this research was to examine the role of online activism in wellbeing, defined here as elements of subjective well-being (Diener, 1984) and/or psychological well-being (Ryff \& Keyes, 1995; Ryff, 2013; Seligman, 2011). 


\subsection{Activism and well-being.}

Increasing evidence shows that taking a wide range of offline actions against injustice is good for well-being (see Vestergren, Drury \& Chiriac, 2016 for a review). For example, individual confrontations of everyday sexism predict increasing self-assurance and life satisfaction over one month (Foster, 2013), participation in political protest demonstrations predicts empowerment (Drury, Cocking, Beale, Hanson \& Rapley, 2005; Evripidou \& Drury, 2013), and activists report greater happiness (Boehnke \& Wong, 2011) and psychological wellbeing (Klar \& Klasser, 2009).

Online activism can be conceptualized as a type of activism referred to as "consensus mobilization" (Klandermans, 1984) or "persuasive action" (Brunsting \& Postmes, 2002; Postmes \& Brunsting, 2002). Consensus mobilization occurs when "a social movement tries to obtain support for its point of view. It is directed towards influencing knowledge, beliefs and attitudes" Klandermans, 1984; p. 107). When individuals are trying to inform or convince others that "a certain state of affairs is unacceptable and can be changed" (Klandermans, 1987, p. 519), they are participating in consensus mobilization/persuasive action. Some pre-online forms of this type of activism have included letter writing (Foster \& Matheson, 1995; Klandermans, 1997) or signing a neighborhood petition (Louis, 2009; Kelly \& Breinlinger, 1995). In the digital age, signing online petitions, sending emails and/or tweeting may serve as a technological variation

of consensus mobilization. As such, it would be expected that online forms of activism can also lead to well-being. However, there is sparse empirical work on whether this is the case. In support, experimental work has shown that tweeting about sexism leads to greater well-being compared to control groups (Foster, 2015). Yet certainly, contrary evidence also exists: greater 
social media use (including use of Black-woman oriented hashtags e.g., \#BlackGirlsRock) predicts more depression and anxiety (Stanton, Jerald, Ward \& Avery, 2017). As such, it is important to understand the processes through which online activism may or may not promote well-being. Indeed, understanding these processes may be particularly important as online activism becomes more ubiquitous (e.g.,\#DistractinglySexy; \#MeToo; \#TimesUp) and is often a platform of choice among women and other disenfranchised groups (Duggan, 2015; Murthy, Gross \& Mensavalle, 2015; Sutton \& Pollock, 2000).

\subsection{Processes through which activism may benefit well-being}

Why activism in general may serve to enhance well-being has, for the most part, been attributed to the fact that it is a by-product of social identity (i.e., the extent to which we identify/connect with our social groups; (Tajfel \& Turner, 1986)). In turn, social identity is a well-known means of enhancing well-being. The benefits of social identity for physical and mental health benefits are so evident that it is a phenomenon that has been referred to as "the social cure" (Jetten, Haslam \& Haslam, 2012). For instance, social identity protects against depression (Cruwys, Dingle, Haslam, Haslam, Jetten \& Morthon, 2013), cognitive decline in older adults (Haslam, Cruwys, \& Haslam, 2014), improves eating disorder recovery (McNamara \& Parsons, 2016), adolescent resilience (Scarf et al., 2016), and may even enhance the protective capacity of the hormone, oxytocin (Matheson, McQuaid \& Anisman, 2016), to name a few benefits.

One of the earliest theories to link the well-being benefits of social identity to discrimination in particular, is the rejection identification model (RIM; Branscombe, Schmitt \& Harvey, 1999). According to the RIM, when group members view discrimination as pervasive, 
there are negative physical and mental health consequences (see Schmitt, Branscombe, Postmes \& Garcia, 2014 and Pascoe \& Smart Richman, 2009 for reviews). These consequences however, can be alleviated by an adaptive response to perceiving that rejection, namely increasing one's social identity, which in turn increases well-being. This pattern of relationships has been referred to as the "rejection-identification-well-being protection process" (Branscombe, Fernández, Gómez \& Cronin, 2012, p. 119). There has been support for this model across a range of disadvantaged group members: women (Bourguignon, Seron, Yzerbyt, \& Herman, 2006; Schmitt, Branscombe, Kobrynowicz \& Owen, 2002), African Americans (Branscombe, Schmitt \& Harvey, 1999; Postmes \& Branscombe, 2002), Latino Americans (Armenta \& Hunt, 2009; Cronin, Levin, Branscombe, van Laar \& Tropp, 2012), multi-racial groups (Giamo, Schmitt \& Outten, 2012), immigrants (Bourguignon et al., 2006), older adults (Garstka, Schmitt, Branscombe \& Hummert, 2004; Jetten \& Pachana, 2012) and socially stigmatized groups (Fernández, Branscombe, Gómez \& Morales, 2012; Jetten, Branscombe, Schmitt \& Spears, 2001). The pattern is the same across all these groups: the more they perceive discrimination as pervasive, the stronger their identification with their targeted group becomes, and in turn, well-being increases.

However, perhaps because activism is not explicitly part of the RIM (Branscombe et al., 1999), there is sparse research on how these two separate but related predictors of well-being may combine to benefit well-being. The few studies linking the RIM and activism (Molero, Fuster, Jetten, \& Moriano, 2011; Outten \& Schmitt, 2015), have done so with the theoretical assumption that activism is solely an outcome of social identity. While this is certainly a logical assumption, given social identity is a consistent predictor of activism (Tajfel \& Turner, 1986; van 
Zomeren, Postmes \& Spears, 2008), recent theoretical extensions of social identity theory

(Tajfel \& Turner, 1986) suggest that activism may have its own unique benefits, not simply as a by-product of social identity, but because activism can serve to strengthen and solidify social identity. The elaborated social identity model (ESIM; Drury \& Reicher, 1999) and the dynamic dual pathway model (DDPM; van Zomeren, Leach \& Spears, 2012) emphasize the dynamic nature of the relationship between social identity and activism, suggesting that it can be transformative (Drury, Evripidou, van Zomeren, 2015; Drury \& Reicher, 2000, 2005). By "putting one's identity into action" (van Zomeren et al., 2012, p. 187), activism serves as a tangible piece of evidence that group members' connection to the group is an agentic one, enhancing feelings of empowerment, and positive emotion, thereby solidifying their identification with the group (Drury et al., 2005; Drury et al., 2015; Drury \& Reicher, 2005; van Zomeren, Leach \& Spears, 2010; van Zomeren et al., 2012). It stands to reason then, that if activism can strengthen social identity, then it could also strengthen the protective qualities of social identity. As such, the rejection-identification-well-being-protection process, (i.e., the pattern of relationships whereby perceiving pervasive discrimination increases social identity, which in turn, increases well-being), should be strongest among those participating in activism.

Yet, there is little research testing this possibility. One study (Cronin et al., 2012) has recognized the dynamic relationship between social identity and activism when examining the RIM. It showed that, among Latino Americans, activism at year 1 predicted ethnic identification at year 4, which in turn predicted well-being at year 4 . Although supportive of the hypothesis that activism plays a predictive role in enhancing well-being, it did not directly assess whether the rejection-identification-well-being protection process is moderated by taking action, nor did 
it examine online activism. Moreover, the few studies that have explicitly assessed whether RIM (Branscombe et al., 1999) is moderated by various factors (Cruwys \& Gunaseelan, 2016; Ramos et al., 2013; Zagefka \& Jamir, 2015) have not assessed activism (on- or offline). One close exception might be Schumann and Klein (2015) who showed that taking online actions increased participants' sense that their group could be successful, supporting the notion that online activism can solidify a group member's social identity. However, well-being was not assessed.

The current research therefore sought to integrate two related but separate lines of research-the well-being benefits of activism (e.g., Vestergren, Drury \& Chiriac, 2016) and the well-being benefits of social identity (Branscombe et al., 1999) and to do so within the context of online activism. Consistent with theories that speak to the dynamic relationship between activism and social identity (Drury \& Reicher, 1999; van Zomeren et al., 2012), it was proposed that if activism can serve to strengthen social identity (e.g., Drury \& Reicher, 2005; van Zomeren et al., 2010), then it should also enhance the protective ability of social identity. As such, three multi-method studies examined how the rejection-identification-well-beingprotection process may be strengthened by participating in online activism. All studies were conducted in the context of gender discrimination. Study 1 examined women's tweets for linguistic indicators of the relationship between gender identity and well-being; studies 2 and 3 utilized a correlational and experimental design respectively, to assess whether the rejectionidentification-well-being-protection process would be strongest when defining online activism as active vs passive (study 2 ) and when taking online activism vs taking no action (study 3 ). 


\section{Study 1 Overview and Hypothesis}

As delineated in section 1.2, if activism can strengthen social identity (e.g., Drury \& Reicher, 2005) then it should also strengthen the protective qualities of social identity i.e, the ability of social identity to enhance well-being (e.g., Branscombe et al., 1999). It follows, that when participating in online activism against sexism, women's gender identity should be related to well-being. The first study explored this hypothesis in the field, by asking women to read about real-world examples of sexism, and examining their tweets in response to that information. Tweeting was utilized as the operational definition of online activism given women's repeated attempts to mobilize consensus about sexism (e.g., \#DistractinlySexy, \#MeToo, \#TimesUp). Tweets were analyzed using Linguistic Inquiry and Word Count (Pennebaker, Booth, Boyd \& Francis, 2015), and it was expected that linguistic indictors of gender identity would be correlated with linguistic indicators of well-being.

\section{1. Study 1 Method}

\subsubsection{Participants and Procedure}

Female students were recruited to participate using our departmental research experience program. To reduce demand characteristics, participants were told this was a study on "how Twitter affects our thoughts and feelings about information we receive". Consenting participants clicked on a password protected web-link to the questionnaire. They completed age, ethnicity and school major demographics. Self-reported majors $\left(N=70, M_{\text {age }}=19.74, S D=\right.$ 2.30) were $24.3 \%$ Psychology, 18.6\% Business, 15.7\% Sciences (e.g., Biology, Kinesiology), 12.9\% Arts (e.g., Communications, Spanish), 2.8\% Undeclared and due to a data collection error, $25.7 \%$ did not answer the question. Self-reported ethnicity was $62.8 \%$ White/European, $14.3 \%$ 
South Asian, 4.3\% each Chinese, Korean and Latin American, 1.4\% each Black Canadian and West Indian, and $5.7 \%$ identified as "other". $1.5 \%$ chose not to answer the question.

Participants then read the following instructions:

Often, we see information online and want to respond to it. We are interested in how responding to it affects your thoughts/feelings about that social and political information. You have been randomly assigned to view information about how women are devalued in politics. You will read through this information, then tweet your reaction".

2.1.1.2. Portrayal of Sexism. Sexism in politics was then presented to participants with several real articles on sexism that had been previously rated as sexist in past work (Foster, 2015). They clicked through three pages of information, each with a text description, the picture of the actual information depicted on a website and the web link itself for supporting documentation:

- $\quad$ "Did you know that Canada still ranks 53rd in the world when it comes to female representation in politics with only $25 \%$ of women in parliament?

\section{(http://www.ipu.org/wmn-e/classif.htm).}

- Although politicians are elected to represent everyone, negative attitudes toward women from politicians are common. For example, when addressing a graduating class, Canadian MLA representative Doug Elniski told the girls, "men are attracted to smiles...if you want equal, it comes in little packages at Starbucks" (http://www.cbc.ca/news/canada/edmonton/men-are-attracted-to-smiles-alberta-mla-advisedgirls-on-blog-1.808496)

- Not only does devaluing of women occur in the political realm, but media also devalue powerful political women by focusing, not on their abilities, but rather on 
their clothes or body. For example, the British press focuses, not on the ability of female Members of Parliament, but on their physical appearance, picking apart their clothes and body, and infantilizing them by calling them 'girls'

\section{(http://www.theguardian.com/media/2014/jul/16/daily-mail-downing-street-catwalk-female-} $\underline{\text { ministers-outrage) }}$

Upon reading the information they saw the instruction, "Please tweet about the information you received now". These tweets were then copied and pasted from Twitter.com into anonymous Word files to be analyzed in LIWC. Participants were then debriefed.

\subsubsection{Study 1 Measures}

Because the words individuals choose to convey their meanings provide valuable information about psychological processes (Pennebaker \& Chung, 2017; see also Tausczik \& Pennebaker, 2010 for a review), linguistic markers were explored as less obtrusive measures of identity and well-being. Tweets were analyzed using Linguistic Inquiry and Word Count (Pennebaker, Booth, Boyd \& Francis, 2015), a text analysis program that calculates the percentage of total number of words for particular word categories. The categories of interest were chosen for their theoretical and empirical relevance to identity and well-being. Well-being word categories were based on Diener's (1984) subjective well-being construct of greater positive than negative affect, and Seligman's (2011) psychological dimensions of well-being: engagement, relationships, meaning and accomplishments.

Specifically, for positive affect, a difference score was calculated by subtracting the negative words from the positive words such that a higher score represented a greater percentage of positive than negative emotion words in the tweet. Engagement, broadly defined as focused, committed and/or goal-oriented (Csikszemtmihalyi, 1988; 2000), was represented 
by future-oriented words (e.g., anticipate, future), given their relationship to goal-orientation (e.g., De Choudhury, Kumar \& Weber, 2017; see also Tausczik \& Pennebaker, 2010 for a review). Relationships (having social connection; Seligman, 2011) were represented by the affiliation (e.g., ally, bestfriend, share) word category. Meaning (having purpose/meaning in life; Seligman, 2011) was represented by the insight (e.g., think, consider) and causal (e.g., because, effect) word categories, i.e., cognitive processing words that suggest an attempt to find meaning in an event (e.g., Pennebaker, Mayne \& Francis, 1997). Accomplishments were represented by the achievement words category (e.g., accomplish, solving, succeed). Finally, the female word category (e.g., women, she) was used to represent gender identity.

\subsection{Study 1 Results and Discussion}

As expected, Pearson correlations showed that the more participants used female words, the more they used positive emotion words $(r=.24, p=.05)$, future oriented words $(r=$ $.28 p=.02)$, affiliation words $(r=.26, p=.04)$ and achievement words $(r=.40, p=.001)$. There was no relationship between female and insight words ( $r=-.03, p=.81)$, or causal words, although that relationship was in the hypothesized direction $(r=.11, p=.39)$. Thus, consistent with the protective role of social identity for well-being (Branscombe et al., 1999), these data suggest that when participating in online activism in the form of creating tweets in response to sexist information, the more women were focused on their gender, the more their language choices conveyed evidence of well-being.

Granted, the use of linguistic markers to assess these relationships has both strengths and weaknesses. One of its strengths over other forms of content analysis (e.g., Corbin \& Strauss, 2008) is that it relies less on the researcher's idiosyncratic perspective to examine 
content themes, and/or on the subjective opinions of judges to rate those themes. Moreover, given language is, by definition a way to convey people's meanings, the use of linguistic markers to indicate people's thoughts and emotions has been considered a method that produces fewer demand characteristics and is less obtrusive when assessing difficult topics (e.g., Wolf, Sedway, Bulik \& Kordy, 2007). Yet, even with growing validation for the relationship between word choice and psychological processes (e.g., Pennebaker, 2011; Schwartz et al., 2013, 2016; Tausczik \& Pennebaker, 2010), it can also be argued that, for example, a woman using female words in her tweet is not necessarily strongly connected to her gender group, or that using future-oriented words will not guarantee well-being. As such, these relationships need to be corroborated with explicit measures as well.

Additional limitations of this study were that it did not include a measure of perceived discrimination, and as such could not test the full RIM (Branscombe et al., 1999). Moreover, the hypothesis that participation in online activism moderates rejection-identification-well-being protection process could not be tested because although participants were participating in online activism by creating a tweet, it is unclear whether doing so was actually perceived as a form of activism. On the one hand, past research (Foster, 2015) has shown that tweets in response to sexist information do contain themes of collective intent (i.e., reference to group status, group identity, group interests) and consensus mobilization (i.e., naming the problem, criticizing, persuading, suggesting change; Klandermans, 1984) and as such, were intentionally used as online activism. At same time however, tweeting a protest response to injustice does not preclude the belief that doing so is merely a passive means of protest (e.g., "armchair activism; Gladwell, 2010). For activism to have positive impact on well-being, some evidence 
suggests that across a range of actions (informing the media, threatening legal actions, meeting with the discriminator), the actor needs to define those actions as active vs passive behaviours (Foster, 2014). As such, it may be that regardless of participation, as long as online activism is perceived as active, it may be beneficial for well-being. Thus, Study 2 was designed to assess whether perceiving online activism as active would enhance the rejection-identification-wellbeing protection process.

\section{Study 2 Overview and Hypothesis}

To assess whether perceiving online activism as active would enhance the rejectionidentification-well-being protection process, participants completed a questionnaire assessing their belief that online activism is active vs passive, read about sexism in politics, and then completed measures of perceived pervasiveness of sexism, gender identity, and well-being. It was expected that believing online activism is active (vs passive) would moderate the indirect effect of perceiving pervasive sexism on well-being through gender identity. More specifically, it was expected that this moderated mediation (Hayes, 2015) would occur at the second stage of mediation (the path between identity and well-being rather than the first stage (the path between pervasive discrimination and identity) (see Figure 1), such that the indirect effect of pervasive discrimination on well-being through gender identity would be stronger among those believing online activism is active than among those believing online activism is a passive means of protest. This expectation was founded in the theoretical rationale delineated in section 1.2, namely that there is accumulating evidence on the dynamic relationship between activism and social identity (Drury et al., 2005; Drury et al., 2015; Drury \& Reicher, 2005; van Zomeren, Leach \& Spears, 2010; van Zomeren et al., 2012), rather than between activism and perceived 
pervasive sexism. Although the latter is possible (van Zomeren et al., 2012), and will be tested to rule out the competing model, more research supports the effect of activism on identity. As such, moderated was expected at the second stage of mediation.

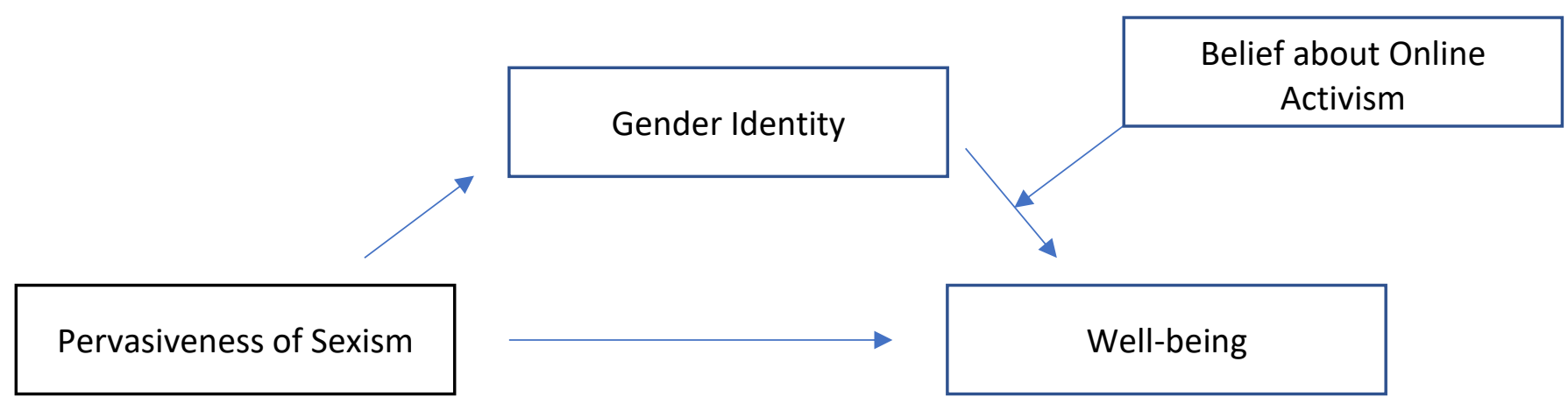

Figure 1. Hypothesized moderated mediation model at the second stage of mediation.

\subsection{Study 2 Method}

\subsubsection{Participants and Procedure}

Given the small correlations in study 1, G*Power (Faul, Erdfelder, Lang \& Buchner, 2007) was used to estimate sample size for a medium effect size, based on past work with similar variables (Foster, 2013, 2014, 2015). To achieve power of .80, the minimum estimate was 92 , however the final sample of undergraduate women was 159; the study was continued so that student volunteers (who do so for course credit) had access to enough studies to meet their course requirements.

To reduce demand characteristics, the study was described as a questionnaire on "how social media/online activism affects our thoughts and feelings about information people receive". Consenting participants clicked on a password protected web-link to the questionnaire and completed same demographics questions described in section 2.1.1. Mean 
age was $19.55(S D=2.01)$. Self-reported ethnicity was: $57.9 \%$ White, $12.6 \%$ South Asian, $8.8 \%$

Chinese, 3.8\% multiple ethnicities, 4.4\% European, 3.1\% Latin American, 3.1\% Black, 1.9\% Arab, 1.9\% Filipino, 1.9\% Korean, .6\% West Indian. Self-reported major was $46.8 \%$ Science (Biology, Psychology, Computer Science \& Physics); 25.3\% Arts; 19.8\% Business; 8.1\% undeclared.

Participants then read the same instructions described in section 2.1.1, except instead of being told to tweet, they read, "You will read through this information, then answer various questions about your personal, social and political opinions." They were then asked one question about their perception of social media/online activism which served as the moderator, and then viewed the same portrayal of sexism in politics described in section 2.1.1.

After reading about sexism, they completed measures of perceived sexism, gender identity, and well-being, in that order. Upon completion of the questionnaire, participants were debriefed.

\subsubsection{Study 2 Measures}

3.1.2.1. Active/Passivity of online activism. Before viewing the information on sexism, participants indicated using a scale from 1 (active) to 5 (passive), to what extent they considered social media/online actions against injustice to be active or passive.

3.1.2. Perceptions of Sexism. To check that participants did indeed perceive the information as sexist, they completed measures of the amount of sexism perceived. Participants were asked with respect to the information they read about, "how fairly are the women being treated?" and "how sexist is this treatment?" using a scale ranging from "not at all" (1) to "extremely (5).

To assess the degree to which this sexism was perceived as pervasive several dimensions of pervasiveness were assessed: frequency, pervasiveness in time, across events, 
and likelihood of personal experience with sexism (Branscombe et al., 1999). Using a 5-point scale, participants were asked to think about the articles they read and to indicate, "How often does this issue affect women generally;" "How likely is this type of thing likely to occur again in the future;" "How pervasive in society is this type of thing". Items were coded such that high scores represented greater perceived pervasiveness, and the mean across the questions was used as an overall pervasiveness score $(\propto=.70)$

3.1.2.3. Gender identity. Six items from Cameron's (2004) measure of social identity were used: "I have a lot in common with other women"; "I feel strong ties to other women"; "I don't feel a sense of being 'connected' with other women"; "Overall, being a woman has very little to do with how I feel about myself"; In general, being a woman is an important part of my selfimage"; "The fact that I'm a woman rarely enters my mind". Participants rated each item on scale from "completely disagree" (1) to "completely agree" (5). Items were coded so that high scores reflected strong gender identity and the mean across all items was used as the overall score $(\propto=.75)$

3.1.2. Well-being. Subjective well-being was assessed with positive affect and life satisfaction (Diener, 1984). Using the positive affect sub-scale from the Positive and Negative Affect Schedule-Expanded Form (PANAS; Watson \& Clark, 1994) participants rated 9 adjectives (active, attentive, alert, determined, enthusiastic, excited, inspired, interested, proud) on the extent to which they "feel this way, right now". The average across the items was used as the overall positive affect score $(\propto=.84)$. Due to experimenter error however, the negative adjectives were missing from the dataset. 
Life satisfaction was assessed using Diener's 5-item (e.g., "In most ways, my life is close to my ideal") life satisfaction scale (Diener, Emmons, Larsen \& Griffin, 1985). Participants were instructed to think about their life, and how beliefs about 'how life is going' may change from day to day. They were asked to consider each statement in terms of "how you feel about your life right now". High scores reflected high life satisfaction; the mean across the items was used as the overall life satisfaction score $(\propto=.90)$.

Psychological well-being was measured using Ryff and Keyes' (1995) 18-item short form scale (e.g., "I have confidence in my opinions, even if they are contrary to the general consensus", "I am quite good at managing the many responsibilities of my daily life"). Participants indicated how much "each statement describes yourself, right now". Items were coded so that high scores reflect high well-being; the mean across all items was used as the overall well-being score $(\propto=.80)$.

All three well-being measures used the same scale ranging from "very slightly/not at all" (1) to "extremely" (5).

\subsection{Study 2 Results and Discussion}

\subsubsection{Amount of Perceived Sexism}

For sexism to have been successfully portrayed, participants should report scores below the midpoint of the scale (3) for fairness and above the midpoint on sexism. One sample t-tests showed that participants rated women's treatment to be significantly lower (i.e., perceived unfairness), $t(156)=-27.06, p<.0001,95 \% \mathrm{Cl}[-1.67,-1.44]$ and higher (i.e., perceived sexism) than the midpoint, $t(156)=20.27, p<.0001,95 \% \mathrm{Cl}[1.28,1.56]$ on the fairness and sexist items, 
respectively (see Table 1 for means and correlations). Thus, participants perceived the information to be unfair to women and sexist.

Table 1

Descriptive statistics, Correlations among Study 2 variables

\begin{tabular}{|c|c|c|c|c|c|c|c|c|c|c|}
\hline & $M$ & $S D$ & 1 & 2 & 3 & 4 & 5 & 6 & 7 & $\underline{8}$ \\
\hline 1. Active & 3.63 & 1.02 & - & -.09 & .11 & $.22 * *$ & .10 & -.06 & .08 & $-.15+$ \\
\hline 2. Fair & 1.45 & 0.62 & & - & $-.41 * *$ & $-.46 * *$ & $-.23 * *$ & .10 & .07 & -.11 \\
\hline 3. Sexist & 4.42 & 0.89 & & & - & $.53 * *$ & $.24 * *$ & -.11 & -.08 & .14 \\
\hline 4. Pervasive & 4.01 & 0.63 & & & & - & $.28 * *$ & -.07 & $-.15+$ & .08 \\
\hline 5. Identity & 3.63 & 0.69 & & & & & - & .07 & .03 & $.18^{*}$ \\
\hline 6. Positive Affect & 2.42 & 0.76 & & & & & & - & $.25^{* *}$ & .07 \\
\hline 7. Life Satisfaction & 3.13 & 0.92 & & & & & & & - & $.44^{* *}$ \\
\hline 8. Well-being & 3.61 & 0.49 & & & & & & & & - \\
\hline
\end{tabular}

Note. $+p<.07, * p<.05, * * p<.01$. Scores range from 1 to 5 .

\subsubsection{Main analysis}

To test for moderated mediation, Hayes' Process (2018) custom dialog for SPSS (model 14) was used. This model tests whether the indirect effect of perceived pervasiveness on wellbeing through gender identity is moderated at the second stage of mediation, namely the path between gender identity and well-being. Variables were mean centred and unstandardized coefficients are reported. Three separate models were run, one for each measure of well-being (see Table 2). 
Table 2

Indirect effects of pervasiveness on well-being variables through gender identity for study 2

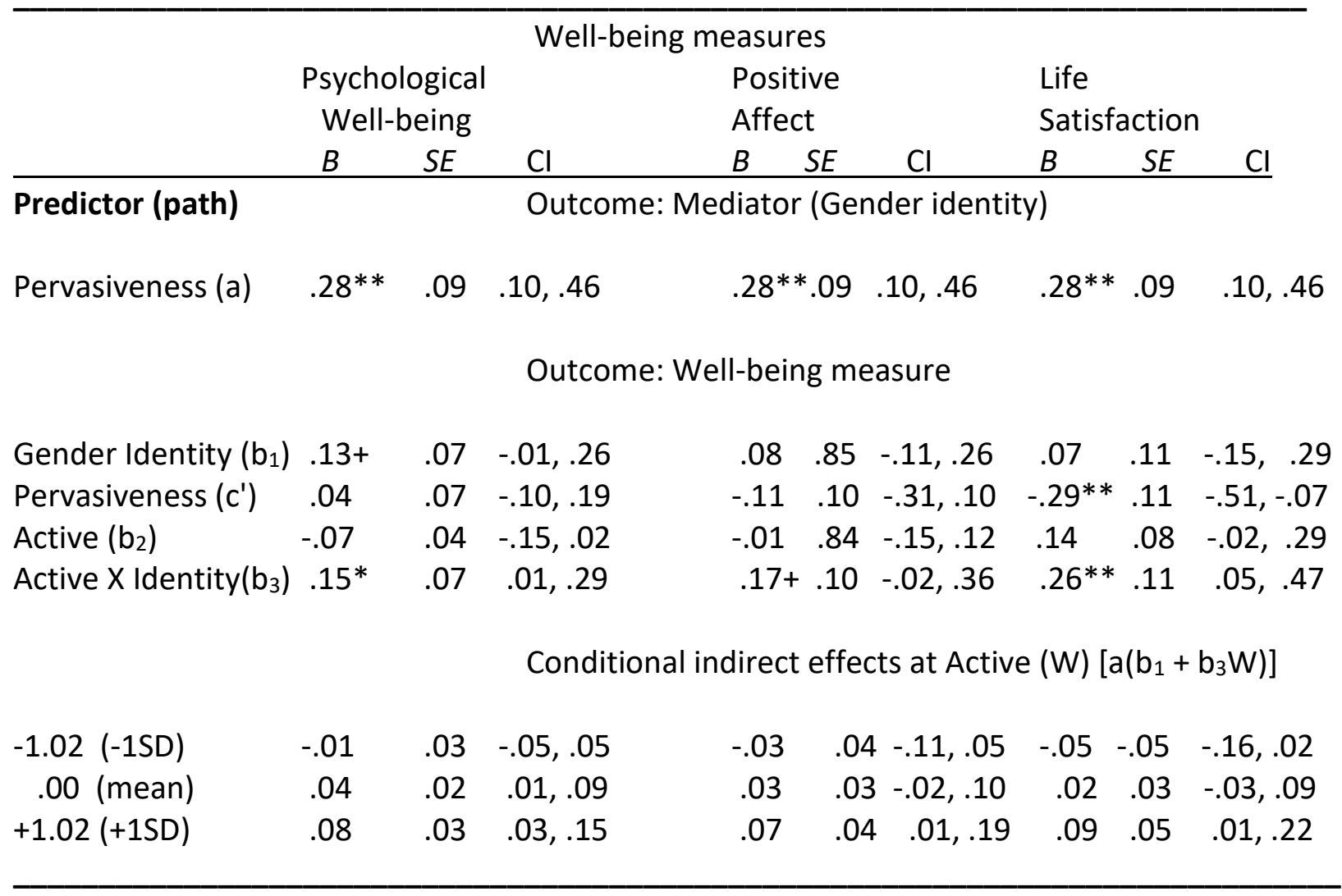

Note. $+p<.07, * p<.05, * * p<.01$. Path a is the same across all outcomes because moderated mediation is occurring at the second stage of mediation (gender identity-well-being) rather than the first stage (pervasiveness-gender identity).

The index of moderated mediation (Hayes, 2015), which is the omnibus test of whether the indirect effect varies across levels of the moderator, was tested using a bias-corrected $95 \%$ bootstrap confidence interval based on 5000 samples. The indices for psychological well-being, positive affect and life satisfaction were: $.04,(S E=.02) ; .05(S E=.03) ; 07,(S E=.03)$, respectively. None of the confidence intervals contained zero, $\mathrm{Cl}_{\text {psychological well-being }}[.01, .09]$; $\mathrm{Cl}_{\text {positive affect }}[.002, .12] ; \mathrm{Cl}_{\text {life satisfaction }}[.02, .16]$ indicating significant moderated mediation, such that the indirect effects increased as did the belief that social media/online activism is active. 
To probe the moderated mediation (akin to simple effects when probing a significant interaction), the conditional indirect effects at 1 SD above (online activism is 'active') and 1 SD below (online activism is 'passive') on the moderator were further tested with a bias-corrected 95\% bootstrap confidence interval based on 5000 samples. When online activism was defined as passive, the confidence interval contained zero for all three measures of well-being, indicating no significant indirect effects of pervasiveness on well-being through gender identity. Thus, for those believing social media/online activism is passive, the rejection-identificationprotection-well-being process did not hold. This suggests that among those who believe online activism is a passive response to injustice, gender identity was not protective for well-being. In contrast, when online activism was defined as active, confidence intervals did not contain zero for all three measures of well-being, indicating that among those believing that social media/online activism is active, there were significant indirect effects of pervasiveness on well-being through gender identity. Specifically, as perceived pervasiveness of sexism increased, so did the strength of gender identity (path a), which in turn predicted greater wellbeing $^{1}$ (conditional paths $b=.28$ for psychological well-being; .25 for positive affect; .33 for life satisfaction). Thus, consistent with the hypothesis, the rejection-identification-well-beingprotection process held for those who considered social media/online activism to be active, but not for those who considered it to be passive. Consistent with theories that suggest activism can strengthen social identity (Drury \& Reicher, 1999; van Zomeren, Leach \& Spears, 2012), online activism appears to also strengthen the protective properties of social identity. This could be important in situations where women are nervous about taking large-scale actions 
against discrimination because of possible repercussions. As long as they consider their online activism to be active, their psychological health may be benefitted.

Because of the order in which measures were completed (section 3.1.2.), whereby the moderator was assessed before all other measures, a competing model was also tested: a firststage moderated mediating model (Hayes, 2015) whereby the indirect effect of perceived pervasiveness on well-being through social identity is moderated by activism at the first stage of the mediation, namely the relationship between perceived pervasiveness and gender identity (path a). However, all the indices of moderated mediation contained zero, indicating the indirect effect was not significantly moderated at the path between pervasiveness and gender identity $\left(b_{\text {psychological well-being }}=.01, S E-.02,95 \% \mathrm{Cl}[-.002, .04] ; b_{\text {positive affect }}=.01, S E=.01\right.$, $\left.\left.95 \% \mathrm{Cl}[-.005, .05] ; b_{\text {life satisfaction }}=.007, S E=.02,95 \% \mathrm{Cl}=-.004, .05\right]\right)$. Instead, consistent with past research (e.g., Branscombe et al., 1999) perceived pervasiveness predicted increased gender identity regardless of beliefs about online activism. This suggests that believing social media/online activism is active vs passive appeared to be important for maintaining social identity's protective properties, rather than a means of enhancing social identity as an adaptive response.

Granted, this was a correlational design where the measure of action was a perception about online activism rather than action-taking itself. Study 3 was therefore designed to replicate these findings by randomly assigning participants to an email protest condition or a no-action control. It was again (see section 3) hypothesized that the indirect effect of perceived pervasiveness of sexism on well-being through increased gender identity would be moderated at the second stage of mediation. 


\section{Study 3 Method}

\subsection{Participants}

The goal was to recruit 100 participants (50/condition; Simmons, Nelson \& Simonsohn, 2013) to achieve power of .80 but only 89 undergraduate women from the same university's psychology department participant pool volunteered to participate for course credit. 82 participants were between 18-21 years of age; 4 were between 22-25; and 2 participants were 41 or older; 1 did not report age. Self-reported ethnicity was: 57.3\% White, 6.7\% South Asian, 6.7\% European, 4.5\% Latin American, 3.4\% Black, 3.4\% multiple ethnicities, 2.2\% Chinese, 2.2\% Arab, 1.1\% First Nations and $12.4 \%$ did not answer. Self-reported major was $38.9 \%$ Science, $37.6 \%$ Arts, $13.5 \%$ undeclared, 10\% Business.

\subsection{Procedure}

To reduce demand characteristics, the study was described to participants as an investigation into

"how people make decisions about which politicians they support and how they feel about those decisions after their choice is made. We will be presenting you with some information about Canadian political figures. In some conditions participants will be presented with strengths, and in other conditions participants will be presented with weakness information. Your condition was randomly selected to receive the weakness information, so you will hear about various Canadian politicians that have had the reputation for being sexist.

\subsubsection{Portrayal of Sexism}


As in the previous studies (section 2.1.1.2), participants read through three articles on real sexism within politics:

- Belinda Stronach was a Conservative MP and switched to the Liberal party. Instead of being criticized on political strategy, her gender was targeted, something that has not happened to other MPs who have crossed the floor. As you can see from this report, she was called a whore, and a dipstick, 'albeit an attractive one' by male MPs Bob Runciman and Tony Abbott. (http://www.cbc.ca/news/canada/sexism-cited-inreaction-to-stronach-move-1.547498)

- Another example of this, a few years later was the Ontario Finance Minister Dwight Duncan who, at a gathering of the province's top business people, referred to a female MP in a sexual way rather than a profession one: "it was hard being the 'nonsexy' Liberal', adding that she had better legs than him.

(http://toronto.ctvnews.ca/finance-minister-under-fire-over-sexy-comments-

\section{$1.264349-$ )}

- And Doug Elniski, famous for his comment...(see section 2.1.1.)

After viewing this information participants were asked to ostensibly provide their opinions about this information before moving on to the second part of study. In reality, these questions were the measures of perceived sexism, followed by gender identity.

\subsubsection{Action Manipulation}

After completing these questions, participants who were randomly assigned to the noaction control condition $(n=44)$ completed the outcome measures (psychological well-being, 
self-esteem, happiness and life satisfaction). In contrast, participants randomly assigned to the action condition $(n=45)$ read:

We would like you to send an email to a governmental watchdog group which monitors the activities of political figures. Your email, which will be constructed through your careful selection of the statements listed below, will be forwarded automatically to the watchdog group, Citizens for Canada (citizensforcanda@gmail.com). These statements allow you educate them on the potential dangers of politician's comments.

Participants then saw three sets of statements labelled "Possible introductory statements (choose 1") [ of 2]"; Possible statements for the body of your response (choose as many as you like)" [of 7]" and "Possible concluding statements (choose 1)" [of 2]. The email they created was not anonymous, as both concluding statements asked for their names (see Appendix). The statements were evidence-based, derived from published psychological research. This method of inducing action was chosen as opposed to asking them to write their own email so that content could be controlled; however, to avoid participants feeling that they were inactively submitting a form letter, they were given the ability to choose statements. After selecting their statements, participants read, "Once you have finished composing your response, please press NEXT and your response will be automatically forwarded to Citizens for Canada (citizensforcanda@gmail.com)". In reality the email was hyperlinked to a fake email created for this study. Upon submitting their email, participants completed outcome measures. Once outcome measures were submitted, participants read a debriefing form that included information on why deception is necessary in social psychological studies, the real purpose of the study, as well as various psychological and social resources. 


\subsection{Measures}

4.3.1. Perceptions of Sexism. Following the presentation of the sexist articles, but before the action manipulation, the amount of sexism perceived was assessed to check that participants interpreted the information as sexism. Participants were asked 4 questions about fairness and sexism. In contrast to study 2, in which two of the three articles portrayed sexism being perpetrated by a system rather than an individual, study 3 presented articles with individual perpetrators. As such, both perceived fairness and sexism were assessed using an item asking about the politicians and an item asking about the system. Participants indicated, using a scale ranging from "not at all" (1) to "extremely (7), "how fair [sexist] do you consider these politicians to be to women" and "how fair [sexist] do you consider the Canadian political system to be to women. The two fairness items were combined for a mean score of perceived fairness and the two sexism items were combined for a mean score of perceived sexism. Spearman Brown split-half reliabilities (Eisinga, te Grotenhuis \& Pelzer, 2013) were .70 and .67, respectively.

To assess the degree to which this sexism was perceived as pervasive, the same dimensions of pervasiveness described in section 3.1.2.2. were used, but with a wider range of items designed to assess pervasiveness as it applied to these politicians, the Canadian system and beyond the Canadian system. Three items assessed the frequency of sexism: "How often do you think: (a) politicians exhibit this kind of behaviour; (b) this kind of thing happens in the Canadian political system in general (e.g., its laws, its election process, other politicians); (c) this kind of thing happens outside of the Canadian political system (in education, social services, workplaces etc.)". Three items assessed the extent to which participants thought they would 
personally experience sexism: "How often would you expect to personally experience sexism:

(a) if you had to deal with these politicians; (b) in the Canadian political system in general; (c) outside of the Canadian political system]. Three items assessed pervasiveness in time: "Do you think this kind of thing is likely to happen again: (a) with these politicians; (b) in the Canadian political system in general; (c) outside of the Canadian political system. The mean score across all 9 items was used as the overall pervasiveness score $(\propto=.91)$.

4.3.2. Gender identity. Gender identity was measured with five items (Jetten, Schmitt, Branscombe, Garza \& Mewse, 2011): "I feel a sense of solidarity with other women"; "I like being with other women"; "I value other women"; "Being a woman is central to who I am"; "I feel proud to be a woman". Participants were asked to what extent they agree/disagree with the statements on a 7-point scale. Items were coded so that higher scores reflected stronger identity and the mean across all items was used as the overall score $(\propto=.79)$

4.3.3. Well-being. Subjective well-being was again assessed with positive affect and life satisfaction; however, the positive affect measure was shorted to a 4-item happiness scale (Lyubomirsky \& Lepper, 1999). Using a 7-point scale ranging from "not a very happy person" (1) to "a very happy person" (7), participants were asked to think about how they feel right now to report their happiness: (a) "I consider myself very happy" (b) "Compared to my peers I consider myself happy." Using a 7-point scale ranging from "not at all" to "a great deal" participants responded to: (c) "Some people are generally not very happy. Although they are not depressed, they never seem as happy as they might be. To what extent does this characterization describe you?"; (d) "Some people are generally very happy. They enjoy life regardless of what is going on, they get the most out of everything. To what extent does this characterization describe 
you?". Items were coded so that high scores reflected high happiness; the mean across the items was used as the overall happiness score $(\propto=.80)$.

Life satisfaction (Diener, et al., 1985) was assessed using the same scale described in section 3.1.2.4. Using a 7-point scale ranging from "strongly disagree" "strongly agree", participants indicated their agreement about how their life is currently. The mean across all 5 items was used as the overall score $(\propto=.91)$.

Self-esteem was also measured using the State Self-Esteem scale (Heatherton \& Polivy, 1991). Participants indicated "how true for you right now" were 20 statements (e.g., "I feel confident about my abilities"). Items were coded so that high scores reflected high self-esteem. The mean across all the items was used as the overall score $(\propto=.90)$.

Because some research has criticized the 18-item scale described in section 3.1.2.4. due to its inconsistent reliability (Van Dierendonck, 2004), a larger, 24-item adaptation of the psychological well-being scale (Ryff \& Keyes, 1995) was used (Cheng \& Chan, 2005). In this study, participants were asked to think about their life "generally", to see if an acute action could influence perceptions of their life overall. They indicated their agreement/disagreement on a 7 point scale ("strongly disagree" to "strongly agree"). Items were coded so that high scores reflected high well-being; the mean across all items was used as the overall score $(\propto=$ .89)

\subsection{Results and Discussion}

\subsubsection{Perceived Sexism}

For sexism to have been successfully portrayed, participants should report scores below the midpoint of the scale (4) for fairness and above the midpoint on sexism. One sample t-tests 
showed that participants rated women's treatment to be significantly lower (i.e., perceived unfairness), $t(88)=-9.04, p<.0001,95 \% \mathrm{Cl}[-1.69,-1.02]$ and higher (i.e., perceived sexism) than the midpoint, $t(88)=9.46, p<.0001,95 \% \mathrm{Cl}[.96,1.47]$ on the fairness and sexist items, respectively (see Table 3). Thus, participants perceived the presented information as unfair and sexist.

Table 3

Descriptive statistics, Correlations among Study 3 variables, collapsed across condition.

1. Fair

\begin{tabular}{llllllllll}
$M$ & $S D$ & 1 & 2 & 3 & 4 & 5 & 6 & 7 & 8 \\
\hline 2.70 & 1.36 & - & -.13 & $-.19+$ & -.10 & .16 & $.19+$ & .13 & .09
\end{tabular}

2. Sexist

$5.21 \quad 1.21$

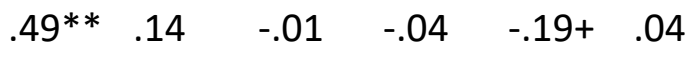

3. Pervasive $\quad 5.15 \quad 0.91$

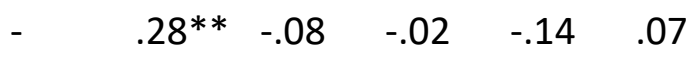

4. Identity

$5.79 \quad 0.09$

.14

$.19+.10 \quad .25^{*}$

5. Happy

$4.78 \quad 1.16$

- $.57 * * .37 * * .56 * *$

6. Life Sat.

$4.76 \quad 1.30$

- $.50 * * .62 * *$

7. Self-esteem $4.35 \quad 0.94$

$-.63^{* *}$

8. Well-being $4.75 \quad 0.73$

Note. $+p<.08, * p<.05,{ }^{* *} p<.01$. Life Sat. refers to Life satisfaction. Scores range from 1 to 7 .

\subsubsection{Main analysis}

As in Study 2, Hayes' Process model 14 (second stage mediated moderation) was used to test whether taking an online action against sexism would moderate the indirect effect of perceived pervasiveness on well-being through gender identity. The competing model 
described in section 3.2.2 was not tested given the procedural order; action was manipulated after perceived discrimination and gender identity were measured and therefore could not be assessed as a moderator of that relationship. The control condition was coded as 0 ; the action condition as 1 . Variables were mean centered and unstandardized coefficients are reported.

Four separate models were run, one for each measure of well-being (see Table 4). 
Table 4

Indirect effects of pervasiveness on well-being variables through gender identity for study 3

\begin{tabular}{|c|c|c|c|c|c|c|c|c|c|c|c|c|}
\hline \multicolumn{13}{|c|}{ Well-being measures } \\
\hline & \multicolumn{3}{|c|}{$\begin{array}{l}\text { Psychological } \\
\text { Well-being }\end{array}$} & \multicolumn{3}{|c|}{ Self-Esteem } & \multicolumn{3}{|c|}{ Happy } & \multicolumn{3}{|c|}{$\begin{array}{l}\text { Life } \\
\text { Satisfaction }\end{array}$} \\
\hline & $B$ & SE & $\mathrm{Cl}$ & $B$ & $S E$ & $\mathrm{Cl}$ & $B$ & SE & $\mathrm{Cl}$ & $B$ & $S E$ & $\mathrm{Cl}$ \\
\hline \multicolumn{13}{|c|}{$\begin{array}{l}\text { Predictor } \\
\text { (path) }\end{array}$} \\
\hline & & & \multicolumn{10}{|c|}{ Outcome: Mediator (Gender Identity) } \\
\hline \multicolumn{13}{|c|}{ Pervasive } \\
\hline \multirow[t]{2}{*}{ (a) } & $.28^{*}$ & $k * .11$ & $.06, .49$ & $.28 * *$ & .11 & $.06, .49$ & $.28 * *$ & .11 & $.06, .49$ & $.28 * *$ & .11 & $.06, .49$ \\
\hline & & & & & \multicolumn{8}{|c|}{ Outcome: Well-being measures } \\
\hline \multicolumn{13}{|c|}{ Gender Identity } \\
\hline$\left(b_{1}\right)$ & $.23^{* *}$ & $* .08$ & $.07, .38$ & $.21^{*}$ & .10 & $.01, .42$ & $.28+$ & .16 & $-.03, .59$ & .33 & .23 & $-.12, .78$ \\
\hline \multicolumn{13}{|c|}{ Pervasive } \\
\hline$\left(c^{\prime}\right)$ & -.02 & $.08-$ & $-.19, .14$ & $-.22+$ & .11 & $-.45, .00$ & -.19 & .16 & $-.50, .12$ & -.13 & .15 & $-.43, .18$ \\
\hline \multicolumn{13}{|c|}{ Action } \\
\hline$\left(b_{2}\right)$ & .22 & $.14-.($ & $.05, .59$ & .20 & .20 & $-.21, .60$ & .20 & .27 & $-.31, .71$ & .18 & .30 & $-.43, .78$ \\
\hline \multicolumn{13}{|c|}{ Act X Gender Identity } \\
\hline \multirow[t]{2}{*}{$\left(b_{3}\right)$} & $.38 * *$ & $* .15$ & $.08, .68$ & .47 & $.21^{*}$ & $.05, .90$ & $.56+$ & .33 & $-.09,1.2$ & .11 & .45 & $-.78, .99$ \\
\hline & & & & & \multicolumn{8}{|c|}{ Conditional indirect effects at Act $(W)\left[a\left(b_{1}+b_{3} W\right)\right]$} \\
\hline \multicolumn{13}{|c|}{ Control $(-.5056)$} \\
\hline & .01 & .03 & $3-.05, .08$ & -.01 & .05 & $-.13, .07$ & -.01 & .05 & $-.09, .11$ & .07 & .09 & $-.43, .31$ \\
\hline \multicolumn{13}{|c|}{ Action (.4944) } \\
\hline & .12 & .05 & $.04, .25$ & .12 & .06 & $.03, .27$ & .15 & .09 & $.02, .38$ & .11 & .07 & $.00, .30$ \\
\hline
\end{tabular}

Note. $+p<.07, * p<.05, * * p<.01$

The index of moderated mediation (Hayes, 2015) for life satisfaction $(b=.03 ; S E=.10)$ was not significant as the $\mathrm{Cl}$ contained zero $[-.17, .25]$. As such, no further probing was 
conducted; this may be because the life satisfaction variable in this study was slightly more skewed $(-.5)$ than in study $2(-.14)$.

For psychological well-being, self-esteem and happiness the indices of moderated mediation were: $.11,(S E=.06) ; .13(S E=.08)$ and $.16(S E=.11)$, respectively. None of the $95 \%$ confidence intervals based on 5000 samples contained zero, $\mathrm{Cl}_{\text {psychological well-being }}[.02, .25]$; $\mathrm{Cl}_{\text {self- }}$ esteem $[.01, .33] ; C_{\text {happiness }}[.01, .44]$ indicating significant moderated mediation, such that the indirect effects increased from the control to experimental condition. To probe the moderated mediation, the conditional indirect effects were also tested with a bias-corrected $95 \%$ bootstrap confidence interval based on 5000 samples. For the no-action control group, the confidence intervals for the conditional indirect effect all contained zero indicating no significant indirect effects of pervasiveness on well-being through gender identity among those who induced to take no action after reading about sexism. Thus, not only was gender identity unable to protect against the negative well-being effects of pervasive sexism when women believed online activism is passive as in study 2 , but the same pattern exists for when they actually were passive.

In contrast, among those who participated in online activism, the confidence intervals for the conditional indirect effects did not contain zero, indicating the significant indirect effects of perceived pervasiveness on greater well-being through gender identity. Specifically, as perceived pervasiveness of sexism increased, so did the strength of gender identity (path a), which in turn was related to greater well-being (conditional paths $b=.42$ for psychological wellbeing; .45 for self-esteem; .56 for happiness) (See Footnote 1 for formula). Thus, the rejection- 
identification-well-being-protection process was maintained not only when participants believed they were active (study 2), but when they were active.

\section{General Discussion}

This research examined the role of online activism in well-being. Although each study operationally defined online activism differently (tweeting; belief that social media/online activism is indeed active; acting by sending an email protest), similar patterns emerged: online activism enhanced the relationship between gender identity and well-being. Specifically, study 1 showed positive correlations between the gender identity words and well-being words being used by women to tweet out responses to sexism, consistent with accumulating evidence showing how identifying with one's social group enhances health and well-being (see Jetten, Haslam, Cruwys, Greenaway, Haslam \& Steffans, 2017 for a review). Moreover, studies 2 and 3 showed that the rejection-identification-well-being-protection process held for those who considered social media/online activism to be active, but not for those who considered it to be passive (study 2 ) and those participating online activism versus not (study 3 ). This is consistent with past work showing that the rejection-identification model can be moderated by various factors (Cruwys \& Gunaseelan, 2016; Ramos et al., 2013; Zagefka \& Jamir, 2015).

These findings further contribute to theories on the dynamic nature of social identity by expanding the definition of what forms of activism may be beneficial for well-being. Although these theories have generally focused on large-scale activism such as protest, the current findings suggest that 1 ) the benefit of activism also applies to online activism, and 2) by participating in online activism, and believing it is an active means of protest, social identity becomes a greater psychological resource, thereby increasing well-being. Thus, the benefits of 
the dynamic relationship between social identity and activism can be expanded to include online activism.

An alternative explanation for these results may be that there is some cognitive dissonance (Festinger, 1957) experienced by not 'practising what you preach' - if perceived pervasiveness of discrimination is strong enough to increase social identity, but then no action is taken to solidify that identity, individuals may feel their inaction is inconsistent with their beliefs. The dissonance that occurs as a function of being inconsistent may in turn reduce the protective benefits of social identity.

A limitation of this research is that the forms of online activism tested were not consistent across studies. Although this consistency in findings across different operational definitions of online activism speaks to the generalizability of the findings, it is also a limitation in that it is still unclear whether an experimental manipulation of tweeting vs not tweeting could moderate the rejection-identification-protection process, or whether the language of an email protest would show the same language patterns. Thus, future research will also need to assess causal impacts of the varied forms of online activism. Another limitation of this research was that these studies only examined a gendered context, and similarly, this work only presented sexism within a context of politics. On the one hand, keeping the type of sexism consistent across studies provides an element of control. Moreover, past work using these sexism primes showed no difference between how these were perceived versus other forms of sexism (Foster, 2015). At the same time however, it is feasible that the type of sexism experienced may moderate the benefits of online activism for enhancing the protective benefits of gender identity. For example, perhaps a form of sexism that takes place in a context 
in which greater social costs may be incurred (e.g., tweeting out about a boss's sexist comment) may not enhance the protective benefits of social identity. Thus, future research will need to confirm whether online activism's ability to maintain the protective benefit of identity is also generalizable to other social groups and other contexts of sexism. Finally, these studies did not examine the reasons why social identity may enhance well-being as a function of online activism. Previous research suggests this may occur through increased social support (Haslam, Reicher, Levine, 2012), collective self-esteem (Jetten et al., 2015) and personal control (Greenaway, Haslam, Cruwys, Branscombe, Ysseldyk \& Heldreth, 2015), but future research will need to test whether enacting a social identity with online activism, will increase our awareness of the support and esteem our group provides to us, and in turn, increase well-being. Despite these limitations, this research suggests that given the well-being benefits of online activism, its practical implications should not be dismissed. The popularity of social media hashtag activism in particular has exploded (\#MeToo; \#TimesUp; \#DistractinglySexy) and it has been referred to as 'empowering for women' (e.g., Bennett, 2014; Blay, 2016; Clark, 2016). More recently, online activism played an important role in choosing Time Magazine's 2017 Person of the Year--the Silence Breakers (Felsenthal, 2018). The popularity of this form of online activism may be due to its ease, as critics argue (Mozorov, 2009), but this research suggests that it may also be due to how it makes women feel. If online activism is able to protect the well-being benefits of gender identity, then women may be continuing to utilize this form of protest because it enhances their well-being. If quick and accessible online action can be used to maintain the protective qualities of social identity against the negative well-being effects of discrimination, then its role in activism warrants further investigation, as people may 
feel sufficiently safe and empowered to participate in subsequent actions (Drury et al., 2005;

Tausch \& Becker, 2013). Additionally, if online actions can be protective, then they may be a means for maintaining the political participation of introverts (Amichai-Hamburger, Wainapel \& Fox, 2002) or a quick way to re-establish the protective benefits of social identity if an in-person action fails. As such, online activism may prove to be important for well-being in that it plays a "use it or lose it" role in social identity's well-being benefits--by not 'using' our social identity via online activism, we may lose its benefits. But by using it, the protective properties of social identity remain. 


\section{References}

Amichai-Hamburger, Y., Wainapel, G., \& Fox, S. (2002). "On the internet no one knows I'm an introvert": Extroversion, neuroticism, and internet interaction. Cyberpsychology \& Behavior, 5, 125-128. https://doi.org/10.1089/109493102753770507

Armenta, B. E., \& Hunt, J. S. (2009). Responding to societal devaluation: Effects of perceived personal and group discrimination on the ethnic group identification and personal selfesteem of Latino/Latina adolescents. Group Processes \& Intergroup Relations, 12, 2339. doi:10.1177/ 1368430208098775

Bennett, J. (September, 2014). Behold the power of \#hashtag feminism. Retrieved June 28, 2017 from http://time.com/3319081/whyistayed-hashtag-feminism-activism/

Blay, Z. (March, 2016). 21 Hashtags that changed the way we talk about feminism. Retrieved June 28, 2017 from http://www.huffingtonpost.ca/entry/21-hashtags-that-changedthe-way-we-talk-about-feminism_us_56ec0978e4b084c6722000d1

Boehnke, K., \& Wong, B. (2011). Adolescent political activism and long-term happiness: a 21year longitudinal study on the development of micro- and macrosocial worries. Personality and Social Psychology Bulletin, 37, 435-447.

Branscombe, N. R., Fernandez, S., Gomez, A., \& Cronin, T. (2012). Moving toward or away from a group identity: Different strategies for coping with pervasive discrimination. In J. Jetten, C. Haslam \& S. A. Haslam (Eds.), The social cure: Identity, health and well-being (pp. 115-131). New York, New York: Psychology Press.

Branscombe, N. R., Schmitt, M. T., \& Harvey, R. D. (1999). Perceiving pervasive discrimination 
among African Americans: Implications for group identification and well-being. Journal of Personality and Social Psychology, 77, 135-149. doi:10.1037/0022-3514.77.1.135

Bourguignon, D., Seron, E., Yzerbyt, V., \& Herman, G. (2006). Perceived group and personal discrimination: Differential effects on personal self- esteem. European Journal of Social Psychology, 36, 773-789. doi: 10.1002/ejsp.326

Brunsting, S., \& Postmes, T. (2002). Social movement participation in the digital age: Predicting offline and online collective action. Small Group Research, 33, 525-554. doi: $10.1177 / 104649602237169$

Cameron, J. E. (2004). A three-factor model of social identity. Self and Identity, 3, 239-262. doi: $10.1080 / 13576500444000047$

Cheng, S., \& Chan, A. C. M. (2005). Measuring psychological well- being in the Chinese. Personality and Individual Differences, 38, 1307-1316. doi:10.1016/j.paid.2004.08.013 Clark, R. (2016). "Hope in a hashtag": the discursive activism of \#WhylStayed. Feminist Media Studies, 16, 788-804. http://dx.doi.org/10.1080/14680777.2016.1138235

Corbin, J., \& Strauss, A. (2008). Basics of qualitative research (3rd ed.). Los Angeles, CA: Sage.

Cronin, T., Levin, S., Branscombe, N. R., van Laar, C., \& Tropp, L. R. (2012). Ethnic identification in response to perceived discrimination protects well-being and promotes activism: $\mathrm{A}$ longitudinal study of Latino college students. Group Processes \& Intergroup Relations, 15, 393-407. doi:10.1177/1368430211427171

Cruwys, T., \& Gunaseelan, S. (2016). "Depression is who I am”: Mental illness identity, stigma and wellbeing. Journal of affective disorders, 189, 36-42. http://dx.doi.org/10.1016/j.jad.2015.09.012 
Cruwys, T., Dingle, G. A., Haslam, C., Haslam, S. A., Jetten, J., \& Morton, T. A. (2013). Social group memberships protect against future depression, alleviate depression symptoms and prevent depression relapse. Social Science and Medicine, 98, 179-186. doi:10.1016/j.socscimed.2013.09.013

Csikszentmihalyi, M. (1988). The flow experience and its significance for human psychology. In M. Csikszentmihalyi \& I. Csikszentmihalyi (Eds.), Optimal experience: Psychological studies of flow in consciousness (pp. 15-35). NY: Cambridge University Press.

Csikszentmihalyi, M. (2000). Beyond boredom and anxiety. San Francisco, CA, US: Jossey-Bass.

De Choudhury, M., Kumar, M., \& Weber, I. (2017). Computational approaches toward integrating quantified self sensing and social media. CSCW: Proceedings of the Conference on Computer-supported Cooperative Work, 1334-1349. doi:10.1145/2998181.2998219

Diener, E. (1984). Subjective well-being. Psychological Bulletin, 95, 542-575. doi:10.1037/00332909.95.3.542

Diener, E., \& Chang, M. Y. (2011). Happy people live longer: Subjective well-being contributes to health and longevity. Applied Psychology: Health and Well-being, 3, 1-43.

Diener, E. D., Emmons, R. A., Larsen, R. J., \& Griffin, S. (1985). The satisfaction with life scale. Journal of personality assessment, 491, 71-75. http://dx.doi.org/10.1207/s15327752jpa4901_13

Drury, J., Cocking, C., Beale, J., Hanson, C., \& Rapley, F. (2005). The phenomenology of empowerment in collective action. British Journal of Social Psychology, 44, 309-328. doi: $10.1348 / 014466604 \times 18523$ 
Drury, J., Evripidou, A., \& van Zomeren, M. (2015). Empowerment: The intersection of identity and power in collective action. In D. Sindic, M. Barreto \& R. Costa-Lopes (Eds.), Power and Identity (pp. 94-116). New York, New York: Psychology Press.

Drury, J., \& Reicher, S. (1999). The intergroup dynamics of collective empowerment:

Substantiating the social identity model. Group Processes and Intergroup Relations, 2, 381-402. doi: $10.1177 / 1368430299024005$

Drury, J., \& Reicher, S. (2000). Collective action and psychological change: The emergence of new social identities. British Journal of Social Psychology, 39, 579-604. doi:

\section{$10.1348 / 014466600164642$}

Drury, J., \& Reicher, S. (2005). Explaining enduring empowerment: A comparative study of collective action and psychological outcomes. European Journal of Social Psychology, 35, 35-58. doi: 10.1002/ejsp.231

Duggan, M. (2015). The demographics of social media users. Pew Research Center. Retrieved October 2, 2016 from http://www.pewinternet.org/2015/08/19/the-demographics-ofsocial-media-users/.

Eisinga, R., te Grotenhuis, M., \& Pelzer, B. (2013). The reliability of a two-item scale: Pearson, Cronbach or Spearman-Brown? International Journal of Public Health, 58, 637-642. http://dx.doi.org/10.1007/s00038-012-0416-3

Evripidou, A., \& Drury, J. (2013). This is the time of tension: Collective action and subjective power in the Greek anti-austerity movement. Contention: The Multidisciplinary Journal of Social Protest, 1, 31-51.

https://doi.org/10.3167/cont.2013.010103 
Fatkin, J-M. \& Lansdown, T. C. (2015). Prosocial media in action. Computers in Human Behavior, 48, 581-586. http://dx.doi.org/10.1016/j.chb.2015.01.060

Felsenthal, E. (2018). The Choice. Time.com. Retrieved January 26, 2018 from http://time.com/time-person-of-the-year-2017-silence-breakers-choice/

Fernández, S., Branscombe, N. R., Gómez, Á., \& Morales, J. F. (2012). Influence of the social context on use of surgical-lengthening and group-empowering coping strategies among people with dwarfism. Re-habilitation Psychology, 57, 224-235. doi:10.1037/a0029280

Festinger, L. (1957). A theory of cognitive dissonance. Evanston, IL: Row, Peterson

Faul, F., Erdfelder, E., Lang, A.-G., \& Buchner, A. (2007). G*Power 3: A flexible statistical power analysis program for the social, behavioral, and biomedical sciences. Behavior Research Methods, 39, 175-191

Foster, M. D. (2013). The personal costs and benefits of responding to discrimination: Behavioral responses and well-being over time. International Journal of Psychological Studies, 5, 135-154. doi: 10.5539/ijps.v5n3p135

Foster, M. D. (2014). The relationship between collective action and well-being and its moderators: pervasiveness of discrimination and dimensions of action. Sex Roles, 70, 165-182. doi: 10.1007/s11199-014-0352-1

Foster, M. D. (2015). Tweeting about sexism: The well-being benefits of a social media collective action. British Journal of Social Psychology, 54, 629-647. DOI: $10.1111 /$ bjso.12101.

Foster, M. D., \& Matheson, K. (1995). Double relative deprivation: Combining the personal and political. Personality and Social Psychology Bulletin, 21, 1167-1177. doi:10.1177/ 
01461672952111005

Garstka, T. A., Schmitt, M. T., Branscombe, N. R., \& Hummert, M. L. (2004). How young and older adults differ in their responses to perceived age discrimination. Psychology and Aging, 19, 326-335. doi: 10.1037/0882-7974.19.2.326

Giamo, L. S., Schmitt, M. T., \& Outten, H. R. (2012). Perceived discrimination, group identification, and life satisfaction among multi-racial people: A test of the rejectionidentification model. Cultural Diversity and Ethnic Minority Psychology, 18, 319-328. doi: $10.1037 / a 0029729$

Gladwell, M. (October 4, 2010). Small change. Why the revolution will not be tweeted. The New Yorker. Retrieved June 18, 2018 from https://www.newyorker.com/magazine/2010/10/04/small-change-malcolm-gladwell

Greenaway, K. H., Haslam, A. S., Cruwys, T., Branscombe, N. R., Yessyldyk, R., \& Heldreth, C., (2015). From "We" to "Me": Group identification enhances perceived personal control with consequences for health and well-being. Journal of Personality and Social Psychology, 109, 53-74. http://dx.doi.org/10.1037/pspi0000019

Haslam, C., Cruwys, T., \& Haslam, S. A. (2014). "The we's have it": Evidence for the distinctive benefits of group engagement in enhancing cognitive health in aging. Social Science and Medicine, 120, 57-66. http://dx.doi.org/10.1016/j.socscimed.2014.08.037

Haslam, S. A., Reicher, S., \& Levine, M. (2012). When other people are heaven, when other people are hell: How social identity determines the nature and impact of social support. In J. Jetten, C. Haslam, \& S. A. Haslam (Eds.), The social cure: Identity, health and wellbeing (pp. 157-175). New York, NY: Psychology Press. 
Hayes, A. F. (2018). Introduction to mediation, moderation, and conditional process analysis: $A$ regression based approach (2nd ed.) New York, New York: Guilford Press.

Hayes, A. F. (2015). An Index and Test of Linear Moderated Mediation. Multivariate Behavioral Research, 50, 1-22, doi: 10.1080/00273171.2014.962683

Heatherton, T. F., \& Polivy, J. (1991). Development and validation of a scale for measuring state self-esteem. Journal of Personality and Social Psychology, 60, 895-910. doi:10.1037/0022-3514.60.6.895

Howell, R. T., Kern, M. L., \& Lyubomirsky, S. (2007). Health benefits: meta-analytically determining the impact of well-being on objective health outcomes. Health Psychology Review, 1, 83-136.

Jetten, J., Branscombe, N. R., Haslam, S. A., Haslam, C., Cruwys, T., Jones, J., . . Z Zhang, A. (2015). Having a lot of a good thing: Multiple important group memberships as a source of self-esteem. PLoS ONE, 10(5): e0124609. doi:10.1371/journal. pone.0124609

Jetten, J., Branscombe, N. R., Schmitt, M. T., \& Spears, R. (2001). Rebels with a cause: Group identification as a response to perceived discrimination from the mainstream. Personality and Social Psychology Bulletin, 27, 1204-1213. doi:10.1177/0146167201279012 Jetten, J., Haslam, C., Cruwys, T., Greenaway, K. H., Haslam, C., \& Steffens, N. K. (2017). Advancing the social identity approach to health and well-being: Progressing the social cure research agenda. European Journal of Social Psychology, 47, 789-802 Jetten, J., Haslam, C., \& Haslam, S. A. (2012). The social cure: Identity, health and well-being. New York, New York: Psychology Press. 
Jetten, J., \& Pachana, N. (2012). Not wanting to grow old: A social identity model of identity change (SIMIC) analysis of driving cessation among older adults. In J. Jetten, C. Haslam \& S. A. Haslam (Eds.), The social cure: Identity, health and well-being (pp. 97-114). New York, New York: Psychology Press.

Jetten, J., Schmitt, M. T., Branscombe, N. R., Garza, A. A., \& Mewse, A. J. (2011). Group commitment in the face of discrimination: The role of legitimacy appraisals. European Journal of Social Psychology, 41, 116 - 126. doi:10.1002/ejsp.743

Kelly, C., \& Breinlinger, S. (1995). Identity and injustice: Exploring women's participation in collective action. Journal of Community and Applied Social Psychology, 5, 41-57. doi:10. 1002/casp.2450050104

Klandermans, P. G. (1984). Mobilization and participation in trade union action: An expectancyvalue approach. Journal of Occupational Psychology, 57, 107-120. doi: 10.1111/j.20448325.1984.tb00153.x

Klandermans, B. (1987). Potentials, networks, motivations and barriers: Steps towards participation in social movements. American Sociological Review, 52, 519-531. doi: $10.2307 / 2095297$

Klandermans, B. (1997). The social psychology of protest. Oxford, UK: Blackwell.

Klar, M., \& Kasser, T. (2009). Some benefits of being an activist: Measuring activism and its role in psychological well- being. Political Psychology, 30, 755-777.

Lee, Y-H., \& Hsieh, G. (2013). Does slacktivism hurt activism? The effects of moral balancing and consistency in online activism. In Proceedings of the SIGCHI Conference on Human 
Factors in Computing Systems, 811-820. New York, NY, USA

doi:10.1145/2470654.2470770

Louis, W. R. (2009). Collective action - Then what? Journal of Social Issues, 65, 727-748. doi:10. 1111/j.1540-4560.2009.01623.x

Lyubomirsky, S., \& Lepper, H. S. (1999). A measure of subjective happiness: Preliminary reliability and construct validation. Social indicators research, 46, 137-155. Retrieved from: http://resolver.scholarsportal.info/resolve/03038300/v46i0002/137_amoshpracv

Matheson, K., McQuaid, R. J., Anisman, H. (2016). Group identity, discrimination, and wellbeing: confluence of psychosocial and neurobiological factors. Current Opinion in Psychology, 11, 35-39. http://dx.doi.org/10.1016/j.copsyc.2016.05.005

McNamara, N. and Parsons, H. (2016), 'Everyone here wants everyone else to get better': The role of social identity in eating disorder recovery. British Journal of Social Psychology, 55, 662-680. doi:10.1111/bjso.12161

Milošević-Dordević, J. S., \& Žežilj, I. L. (2017). Civic activism online: Making young people dormant or more active in real life? Computers in Human Behavior, 70, 113-118.

Molero, F., Fuster, M. J., Jetten, J., \& Moriano, J. A. (2011). Living with HIV/AIDS: A psychosocial perspective on coping with prejudice and discrimination. Journal of Applied Social Psychology, 41, 609-626. doi:10.1111/j.1559-1816.2011.00729.x

Morozov E. The brave new world of slacktivism. Foreign Policy, May 19, 2009. Retrieved May 18,2014 from http://neteffect.foreignpolicy.com/posts/2009/05/19/the_brave_new_world_of_slack tivism?wp_login_redirect $=0$ 
Murthy, D., Gross, A., \& Pensavalle, A. (2015). Urban social media demographics: An exploration of Twitter use in major American cities. Journal of Computer-Mediated Communication, 21, 33-49. doi: 10.1111/jcc4.12144.

Outten, H. R., \& Schmitt, M. T. (2015). The more "intergroup" the merrier? The relationship between ethnic identification, coping options and life satisfaction among South Asian Canadians. Canadian Journal of Behavioural Sciences, 47, 12-20.

Pascoe, E. A., \& Smart Richman, L. (2009). Perceived discrimination and health: A meta-analytic review. Psychological Bulletin, 135, 531-554. doi: 10.1037/a0016059

Pennebaker, J. W. (2011). The secret life of pronouns. New York, NY: Bloomsbury Press.

Pennebaker, J. W., \& Chung, C. K. (2007). Expressive writing, emotional upheavals, and health. In H. Friedman \& R. Silver (Eds.), Handbook of health psychology (pp. 263-284). New York, NY: Oxford University Press.

Pennebaker, J.W., Booth, R.J., Boyd, R.L., \& Francis, M.E. (2015). Linguistic Inquiry and Word Count: LIWC2015. Austin, TX: Pennebaker Conglomerates (www.LIWC.net).

Pennebaker, J. W., Mayne, T. J., \& Francis, M. E. (1997). Linguistic predictors of adaptive bereavement. Journal of Personality and Social Psychology, 72, 863-871. doi:10.1037/ $0022-3514.72 .4 .863$

Postmes, T., \& Branscombe, N. R. (2002). Influence of long-term racial environmental composition on subjective well-being in African Americans. Journal of Personality and Social Psychology, 83, 735-751. doi: 10.1037/0022-3514.83.3.735 
Postmes, T., \& Brunsting, S (2002). Collective action in the age of the internet: Mass communication and online mobilization. Social Science Computer Review, 20, 290301. doi: 10.1177/08939302020003006

Ramos, M. R., Jetten, J., Zhang, A., Badea, C., Iyer, A., Cui, L., \& Zhang, Y. (2013). Minority goals for interaction with the majority: Seeking distance from the majority and the effect of rejection on identification. European Journal of Social Psychology, 43, 72-83. doi: 10.1002/ejsp.1915

Ryff, C. D. (2013). Psychological well-being revisited: Advances in the science and practice of eudaimonia. Psychotherapy and Psychosomatics, 83, 10-28.

Ryff, C. D. \& Keyes, C. L. M. (1995). The structure of psychological well-being revisited. Journal of Personality and Social Psychology, 69, 719-727. doi:10.1037/0022-3514.69.4.719

Scarf, D., Moradi, S., McGaw, K., Hewitt, J., Hayhurst, J. G., Boyes, M., Ruffman, T., \& Hunter, J. A. (2016). Somewhere I belong: Long-term increases in adolescents' resilience are predicted by perceived belonging to the in-group. British Journal of Social Psychology, 55(3), 588-599. doi:10.1111/bjso.12151

Schmitt, M. T., Branscombe, N. R., Kobrynowicz, D., \& Owen, S. (2002). Perceiving discrimination against one's gender group has different implications for well-being in women and men. Personality and Social Psychology Bulletin, 28, 197-210. doi:10.1177/0146167202282006

Schmitt, M. T., Branscombe, N. R., Postmes, T., \& Garcia, A. (2014). The consequences of perceived discrimination for psychological well-being: A meta-analytic review. Psychological Bulletin, 140(4), 921. doi: 10.1037/a0035754 
Schumann, S., \& Klein, O. (2015). Substitute or stepping stone? Assessing the impact of lowthreshold online collective actions on onffline participation. European Journal of Social Psychology, 45, 308-322. DOI: 10.1002/ejsp.2084

Schwartz, H. A., Eichstaedt, J. C. Kern, M. L., Dziurzynski, L., Lucas, R.E. Agrawal, M., Park, G.J., Lakshmikanth, S.K., Jha,S., Seligman, M. E. P., Ungar, L., \& Lucas, R. E. (2013). Characterizing Geographic Variation in Well-Being Using Tweets. In ICWSM 2013: Proceedings of the Seventh International AAAI Conferences on Weblogs and Social Media, pp. 583-591.

Schwartz, H.A., Sap, M., Kern, M. L., Eichstaedt, J.C., Kapelner, A., Agrawal, M. Blanco, E., Dziurzynski, L., Park, G., Stillwell, D., Kosinski, M., Seligman, M. E. P., \& Unger, L. (2016). Predicting individual well-being through the language of social media. In Biocomputing 2016: Proceedings of the Pacific Symposium, pp. 516-527.

Seligman, M. E. P. 2011. Flourish: A Visionary New Understanding of Happiness and Well-being. Free Press.

Simmons, J., Nelson, L., \& Simonsohn, U. (2013, January). Life after p-hacking. Paper presented at the annual meeting of the Society of Personality and Social Psychology, New Orleans, LA. Available at SSRN: https://ssrn.com/abstract=2205186

Skinner, B. F. (1971). Beyond freedom and dignity. New York, NY: Knopf.

Stanton, A. G., Jerald, M. C., Ward, M. L., \& Avery (2017). Social media contributions to strong Black women ideal endorsement and Black women's mental health. Psychology of Women Quarterly, 4, 465-478 DOI: 10.1177/0361684317732330 
Sutton, J., \& Pollock, S. (2000). Online activism for women's rights. Cyberpsychology and Behavior, 3, 699-706.

Tajfel, H. \& Turner, J. (1986). The social identity theory of intergroup behavior. In S. Worchel and L. Austin (Eds.), Psychology of Intergroup Relations (pp. 7-24). Chicago, Illinois: Nelson-Hall.

Tausch, N. \& Becker, J. C. (2013). Emotional reactions to success and failure of collective action as predictors of future action intentions: A longitudinal investigation in the context of student protests in Germany. British Journal of Social Psychology, 52, 525-542. doi:10.1111/j.2044-8309.2012.02109.x

Tausczik, Y. R., \& Pennebaker, J. W. (2010). The psychological meaning of words: LIWC and computerized text analysis methods. Journal of Language and Social Psychology, 29, 2454. doi:10.1177/0261927X09351676

Vaccari, C., Valeriani, A., Barberá, P., Bonneau, R., Jost, J. T., Nagler, J., Tucker, J. A. (2015). Political expression and action on social media: Exploring the relationship between lower- and higher-threshold political activities among Twitter users in Italy. Journal of Computer-Mediated Communication, 20, 221-239. doi:10.1111/jcc4.12108

Van Dierendonck, D. (2004). The construct validity of Ryff's Scales of Psychological Well-being and its extension with spiritual well-being. Personality and Individual Differences, 36, 629-643. doi:10.1016/S0191-8869(03)00122-3

van Zomeren, M., Leach, C.W. \& Spears, R., (2010). Does group efficacy increase group identification? Resolving their paradoxical relationship, Journal of Experimental Social Psychology, 46, 1055-1060. doi: 10.1016/j.jesp.2010.05.006. 
van Zomeren, M., Leach, C. W., \& Spears, R. (2012). Protesters as "passionate economists: A dynamic dual pathway model of approach coping with collective disadvantage. Personality and Social Psychology Review, 16, 180-199. doi:10.1177/1088868311430835

Van Zomeren, M., Postmes, T., \& Spears, R. (2008). Toward an integrative Social Identity Model of Collective Action: A quantitative research synthesis of three sociopsychological perspectives. Psychological Bulletin, 134, 504-535. doi: 10.1037/0033-2909.134.4.504

Vestergren, S., Drury, J., \& Chiriac, E. H. (2016): The biographical consequences of protest and activism: a systematic review and a new typology, Social Movement Studies, doi: 10.1080/14742837.2016.1252665

Watson, D., \& Clark, L. A. (1994). The PANAS-X: The Manual for the positive and negative affect scale-Expanded form. University of Iowa, lowa City, IA.

Wolf, M., Sedway, J., Bulik, C. M., \& Kordy, H. (2007). Linguistic analyses of natural written language: Unobtrusive assessment of cognitive style in eating disorders. Eating Disorders, 40, 711-717. https://doi.org/10.1002/eat.20445

Zagefka, H., \& Jamir, L. (2015). Conflict, fear, and social identity in Nagaland. Asian Journal of Social Psychology, 18, 43-51. doi: 10.1111/ajsp.12076 
Appendix

Statements for Email response

Possible Introductory Statements (Please choose 1):

Hello, I would like to take this opportunity to provide you with some information about why such comments by politicians should be sanctioned.

Dear Board Members, I am writing to inform you of some facts that suggest such comments by politicians are inappropriate.

Possible Statements for the body of your response (Choose as many as you like)

I believe that more action needs to be taken when such comments are made about women by our politicians; such comments are not made about ethnic groups to the same extent they are repeatedly made about women.

Such comments have a very negative effect on how the Canadian political system is viewed by the public.

One of the problems is that discrimination against women has a negative effect not only the obvious such as economic disparities, but on their health-did you know that the more women experience discrimination, the more they report mental health problems like depression, anxiety and reduced well-being? Research also shows they have more stress hormones and participate in dangerous behaviours like smoking and drug use.

While these politicians may argue it was "just a joke", sexist jokes may seem harmless, but actually, they have dangerous consequences. Research shows that men who enjoy sexist humour agree with attitudes about rape, for example, that if a woman dresses in short skirts, she's asking to be raped. This research also shows that the more men enjoy sexist humor the more they report forcing themselves on a woman.

There is research showing that when men are exposed to sexist humour, they are more tolerant of sexist acts; in one study they were more likely to cut funding to a campus women's organization than other organizations. In another, they were more tolerant of an employer's patronizing behavior toward a female employee.

One of the problems with focusing on the sexual aspects of a woman alone is that it leads to seeing women as objects rather than people.

Once we sexually stereotype women, we tend to see them only as objects to be possessed or conquered. And, there is research that the more men see sexually stereotyped images in video games, the more they think its ok to sexually harass women. 


\section{Possible Concluding Statements (Please choose 1)}

Thank-you for taking the time to read this informed response. Sincerely, [insert name]

I appreciate your time and attention to this matter. Sincerely, [insert name] 


\section{Footnote}

${ }^{1}$ Path $b$ (from the mediator to the outcome controlling for the predictor) in a second stage moderated mediation $=b_{1}+b_{3} W$, where $W$ is the a value of the moderator. 